Jen Chen, general manager of Genelabs Biotechnology, a start-up company in Hsinchu that is performing clinical trials for western pharmaceutical companies, agrees that clinical trials for Asia are a niche that Taiwan can develop in biotechnology. But he points out that the severe shortage of doctors who know how to do clinical trials is a serious problem for Taiwan. Genelabs employs its own doctor trained in clinical trial practice to lead projects at hospitals.

"Only when the presidents of top medical institutions, such as the medical school of NTU and Taipei Veterans General Hospital, stand up and say that they are going to focus on clinical trials will things begin to happen," says Chen.

Others are more sceptical about the development of biotechnology in Taiwan. John Yu, first vice-president and general manager of the technology department of the China Development Industrial Bank, the largest investment bank in the Asian-Pacific region outside of Japan, agrees that private funds for investment in biotechnology have grown significantly in recent years. Two-fifths of the US $\$ 50$ million investment fund Yu oversees is earmarked for biotechnology. The fund has risen to this level rapidly over the past three years, with most activity taking place this year.

But all of Yu's major biotech investments are in the United States and mainland China, and he sees little opportunity for worthwhile local investment at present. "People neglect the fact that the semiconductor industry and biotech are totally different. We don't have the brain power or environment to develop biotechnology," he says.

\section{Switching sides}

In general, academics in Taiwan are unwilling to get involved in venture businesses, and the few who do take the plunge find themselves hampered by government regulations. The rules have been eased in recent years, allowing academics to share in the spoils of intellectual property rights. But the ability to work in industry, which depends on respective university's polices, is severely restricted with some of the more lenient universities allowing a sabbatical or a mere 8 hours per week to devote to an industry position. For those serious about their enterprise, the solution is often to leave academia all together.

Rong-hwa Lin, for example, recently resigned from his job as director of the Graduate Institute of Immunology at the National Taiwan University College of Medicine to defect to the private sector. Together with Herbert Wu, an associate professor in the Institute of Molecular Medicine, he is putting the finishing touches to their start-up company, AbGenomics.

Lin and Wu have devised a method for preparing antibodies using DNA immunization. Although many researchers around the world have dismissed this type of technique, AbGenomics is already establishing collaborative agreements with big-name research institutes and universities in Taiwan and in the West, including with the National Institutes of Health (NIH) in the United States.

The NIH showed interest after Lin and $\mathrm{Wu}$ generated antibodies to two cancerrelated proteins from genes it supplied. The $\mathrm{NIH}$ had been trying in vain for three and a half years to prepare the antibodies; Lin and Wu succeeded in less than two months.

But Lin remains concerned about the university regulations he feels impeded his research, especially the government stipulation that after three years a research assistant cannot receive another pay rise. With such poor prospects, few stay for long. "I felt like I was spending half my time retraining research assistants," Lin says. In the private sector, Lin and Wu can pay research assistants according to their performance, rather than just a standard low wage. "Research assistants can treat it as a real job - one they'll want to stay at," Lin says.

Fleeing the regulations of academia, Lin and Wu were also wary of restrictions often imposed by investors. They chose investors who understood biotech and who did not blink when told that they might be looking at a 3-5 year start-up period. The fact that they could be selective points to the startling amount of money available for biotech.

\title{
The rodent route to celebrity
}

Mice have made Hung Li a celebrity in Taiwan's science community. In January this year, Li's paper detailing his mouse models for a fatal motor neuron disease appeared in Nature Genetics (24, 66-70; 2000). On a small island where scientists have only recently started publishing in major journals, this caused quite a stir.

But drowning out the domestic acclaim has been an inundation of requests from overseas laboratories seeking

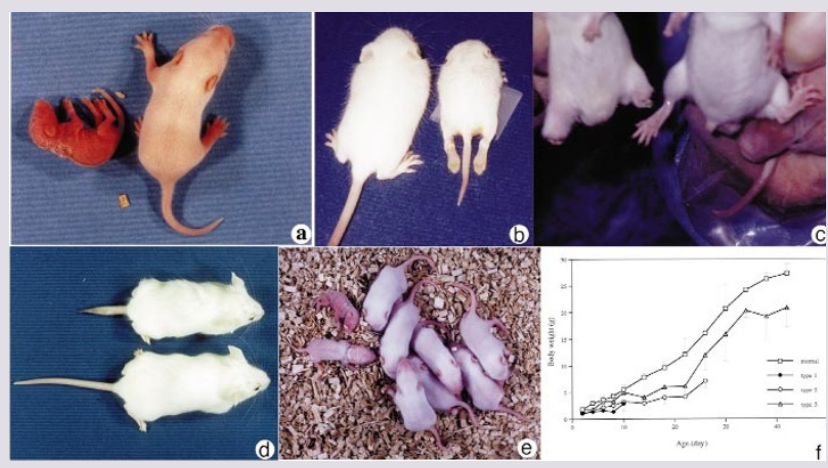

Million dollar mice: Li's rodent models have huge potential. the licensing rights to Li's mice and his results.

Li's research, carried out at his lab in the Academia Sinica's Institute of Molecular Biology, has specific applications for studying spinal muscular atrophy (SMA). Usually appearing in infants, this disease weakens the muscles and often leads to respiratoryrelated fatality.

To tackle the problem, Li generated genetically generated genetically from a form of human SMA. He then used them to screen drug candidates. Two patents are now in the offing, and biotech companies in the United States and Taiwan are offering around US\$1 million for the mice and/or related research results.

But Li would have to share any royalties with his department, the academy and the government. More importantly, any negotiations must be done through the academy, and Li must follow their stipulations concerning publication of his research.

With the patent for the mouse model safely filed, it is now available to drug screeners, and the Academia Sinica has recently signed a contract allowing a Taiwanese biotech start-up to use the mice. But the SMA drug patent is still sitting in a lawyer's office in the United States, waiting to be filed.

$L i$ is learning an unpleasant

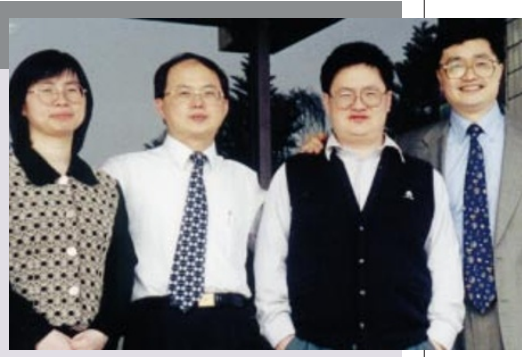

Hung $\mathrm{Li}$ (second from right) and the team behind the mice.

lesson about the effect of patent red-tape not only on licensing but also on research publication. Because Japan and the European Patent Office do not recognize a patent filed after the research underlying it has been published (unlike the United States, which offers a one-year period to file), Li must wait to publish his drug research data.

Li is not so concerned about the money. But he is somewhat vexed by the delay caused by the patenting process and the subsequent accusations made by biotech companies that he is holding up drug development. 